\title{
Effects of gastrointestinal cannulation and jugular vein catheterization on the metabolism of sheep
}

\author{
By J. C. MacRAE, J. S. SMITH AND F. WHITE \\ Rowett Research Institute, Greenburn Road, Bucksburn, Aberdeen AB2 9SB
}

(Received 19 October 1981 - Accepted 15 December 1981)

\begin{abstract}
1. Certain digestive and metabolic criteria were examined in mature wethers before and following (1) a simple exploratory laporotomy (two sheep), (2) establishment of a rumen cannula plus simple (" $\mathrm{T}$ "-shaped) cannulas in the duodenum and ileum (six sheep), (3) establishment of a rumen cannula plus two cannulas in the caecum (four sheep), (4) establishment of a rumen cannula plus re-entrant cannulus in the duodenum and ileum (four sheep) and (5) insertion of catheters into both external jugular veins (four sheep).

2. Metabolizability of a standard ration and nitrogen balance and rumen retention time of the sheep were not significantly changed by any of the surgical procedures carried out.

3. The amount of heat produced per unit metabolic weight of the sheep prepared with re-entrant cannulas increased significantly $(21 \pm 5.6 \% ; P<0.001)$.

4. The use of the different preparations in digestive and metabolic studies is discussed.
\end{abstract}

Many investigations of the energy and nitrogen metabolism of ruminants involve the use of surgically-prepared animals. In these experiments it is assumed that animals prepared with various types of cannulation of the digestive system or catheterization of the vascular system or both provide information which is relevant to intact animals. However, very few experiments have tested the validity of this assumption. Thus apart from a few isolated comparisons of the apparent digestibility of rations in pre- and post-operative sheep (Reid et al. 1961; MacRae, 1967; MacRae et al. 1973), in calves (Putman \& Davis, 1965) and in steers (Drori \& Loosli, 1959; Hayes et al. 1964) only one major study (MacRae \& Wilson, 1977) appears to have been reported on the effect of various forms of gastrointestinal (GI) tract cannulation on the digestive performance of ruminants. The last authors found that neither rumen cannulation, nor re-entrant duodenal and ileal cannulation nor simple (' $T$ '-shaped) duodenal and ileal cannulation had any significant effect on the voluntary feed intake or digestion of sheep, but from the wool growth measurements they suggested that re-entrant cannulation might have a detrimental effect on the efficiency of utilization of absorbed nutrients.

As a preliminary to a series of investigations into the utilization of energy-yielding substrates in sheep, it was considered prudent to examine whether the surgical techniques normally used to obtain GI tract digesta and systemic blood can provide information on digestion and metabolism which are relevant to the intact animals. The present paper reports on certain digestive and metabolic criteria of sheep which had received one of three different types of GI tract cannulation or an insertion of catheters into both external jugular veins.

EXPERIMENTAL

Twenty-eight mature Greyface wethers ranging in live weight from 35 to $60 \mathrm{~kg}$ were used in the study. Three experiments were performed.

Expt 1 involved weekly measurement of heat production of four sheep for 2 weeks before and 5 weeks after two of the sheep underwent a simple laparotomy operation.

Expt 2 consisted of a two-stage study of the energy and $\mathrm{N}$ balances, and the rate of rumen outflow of digesta particulate matter in twenty-four sheep, seventeen of which underwent 
GI surgery in which either simple or re-entrant cannulas were established. The measurements were carried out during the 3 weeks immediately before surgery and again when the animals were fully recovered and, under normal circumstances, would have been ready for investigational work (i.e. $2-5$ months post-surgery).

Expt 3 consisted of a two-stage study of the $24 \mathrm{~h}$ heat productions of four of the control sheep from Expt 2 (i.e. animals which did not undergo surgery in Expt 2) for $48 \mathrm{~h}$ immediately before and for $48 \mathrm{~h}$ immediately after the implantation of catheters into both external jugular veins.

\section{Diet}

After being brought in from pasture all sheep received a standard daily ration of $1 \mathrm{~kg}$ Ruminant Diet AA6 (g/kg fresh wt, dry matter 850, N 21.8, ash 89.9, gross energy $14.93 \mathrm{MJ}$ ) except immediately after surgery in Expt 2 when they were given a good-quality dried grass until their appetite had returned to normal.

\section{Experimental procedures}

Expt 1. The four sheep (weighing $50-51 \mathrm{~kg}$ ) were brought in from pasture and held individually in metabolism crates. They were allowed a 2 -week adjustment period before the heat loss of each was measured over a $24 \mathrm{~h}$ period each week for seven consecutive weeks in a direct calorimeter (Pullar, 1969). Immediately following the second measurement, two of the four sheep underwent a simple investigatory laparotomy on the right flank, the position normally incized for intestinal cannulation. At $6 \mathrm{~h}$ after recovery from anaesthesia (halothane-nitrous oxide) they were returned to their metabolism crates.

Expt 2. Initially sixteen sheep (weighing 55-62 kg) were brought in from pasture and housed in individual pens. Over a period of several weeks each was trained to being held in metabolism crates and in respiration chambers. The animals were allocated to four equal groups on the basis of their heat production $\left(\mathrm{kJ} / \mathrm{kg}\right.$ body-weight $\left.(\mathrm{W})^{0.75}\right)$ measured during this training period. Group A animals were subsequently left intact (control group). All the other sheep were subsequently prepared with a rumen cannula (Kay \& McKenzie, 1968) and in addition with either (1) group B, simple (' $T$ '-shaped) cannulas in the proximal duodenum and terminal ileum (Hecker, 1974); (2) group C, two simple cannulas in the caecum (MacRae et al. 1973) or (3) group D, re-entrant cannulas in the proximal duodenum and terminal ileum (Brown et al. 1968). The following determinations were made on each animal before and after surgery and on the intact animals at time intervals corresponding with those of the animals surgically-treated.

(1) The retention time of particulate matter in the reticulo-rumen was estimated from the semi-log plot of faeces concentraion $v$. time following intraruminal injection of ${ }^{103} \mathrm{Ru}$-phenanthroline (Grovum \& Williams, 1973). The marker $(5 \mu \mathrm{Ci} / \mathrm{sheep}$ ) was introduced via the rumen cannula in all surgically-prepared sheep and via hypodermic puncture of the abdominal and rumen walls in the presurgery and control sheep. Voided faeces were collected in two-hourly portions using an automated collection system (McDonald et al. 1979 ) and the mean retention time of digesta particulate matter in the rumen was calculated as the reciprocal of the $k_{1}$ rate-constant (See Grovum \& Williams, 1973); this was determined by least squares analysis of the linear part of semi-log plots.

(2) Losses of $\mathrm{N}$ and energy in urine and faces were determined by collection over $7 \mathrm{~d}$; Urine was collected daily into $50 \mathrm{ml} 8 \mathrm{M}$-sulphuric acid.

(3) The heat production of each animal was measured over the latter $3 \mathrm{~d}$ of a $4 \mathrm{~d}$ confinement in a closed-circuit respiration chamber (Wainman \& Blaxter, 1969).

Two of the four sheep which underwent re-entrant cannulation in the initial stages of Expt 2 did not recover from the operation and so three further animals were trained to 
replace them. As considerable time had elapsed it was decided to run a further five sheep alongside these, three were left as intact controls and two were prepared with rumen plus duodenal and ileal simple (' $T$ '-shaped) cannulas; one of the re-entrants did not recover from the operation.

Energy balances were obtained on these additional seven sheep. The results presented in Table 1 thus include metabolizability and heat production values from seven sheep in group A, six in group B, four in group $\mathrm{C}$ and four in group $\mathrm{D}$. Values for $\mathrm{N}$ balance and retention times refer to the fourteen sheep studied in the initial part of Expt 2.

Expt 3. After completion of the required measurements for Expt 2, four of the control sheep were used in this experiment. Two measurements of $24 \mathrm{~h}$ heat production were obtained for each sheep immediately before and immediately after the surgical insertion of catheters into both external jugular veins.

\section{Sampling and analysis}

Samples of Ruminant Diet AA6 were taken for analysis during ration preparations. Thoughout the $7 \mathrm{~d}$ balance periods daily sub-samples of faeces and urine were stored at $-4^{\circ}$ until the end of each period when they were mixed and sampled for immediate analysis. The $\mathrm{N}$ content of food, faeces and urine were determined by a microKjeldhal method (Davidson et al. 1970). ${ }^{103} \mathrm{Ru}$ activity in faeces was assayed on an ICN Tracer Lab gamma guard 400 automated spectrometer. Weighed amounts of fresh faeces (approximately $3 \mathrm{~g}$ ) were compressed into the bottom $20 \mathrm{~mm}$ of the polypropylene counting tubes, counted and then oven-dried at $80^{\circ}$ to allow calculation of ${ }^{103} \mathrm{Ru}$ activity/g DM. The metabolizability of the Ruminant Diet AA6 was calculated from faecal and urine values obtained over the $7 \mathrm{~d}$ balance period and the methane productions measured in the closed-circuit respiration chamber.

\section{RESULTS}

Values for the metabolizability of the ration and the heat production, $\mathrm{N}$ balance and rumen retention time of the sheep before surgery are shown in Table 1, together with the percentage changes in these criteria following preparation of the various cannulas in Expt 2 and the catheters in Expt 3 (heat productions only).

\section{Metabolizability, $N$ balance and rumen retention time}

There were no significant changes in any of these criteria following establishment of any of the cannulas. There was considerable between-animal variability in both the $\mathbf{N}$ balances and rumen retention times of the animals before surgery (coefficient of variation 22.7 and $40.7 \%$ respectively) and also in the percentage changes in these criteria from the pre- to the post-surgery measurements (see Table 1, residual SD of percentage change, within animals, for $\mathrm{N}$ balance \pm 54.2 and for rumen retention time \pm 17.7 ). However, there was no indication of any major change in any of the criteria consequent upon establishment of any of the cannulas.

\section{Heat production}

The changes in heat production of the four sheep in Expt 1 are given in Fig. 1. There was a decline in heat production in all sheep over the duration of the 7-week experiment. The measurement made $5 \mathrm{~d}$ after surgery in sheep no. 2 was approximately $800 \mathrm{~kJ} / \mathrm{d}$ higher than the interpolation from its previous and subsequent values. Sheep no. 4 also showed an elevation in heat production immediately after surgery of approximately $600 \mathrm{~kJ} / \mathrm{d}$ which then declined linearly over the following 4 weeks.

The heat production values obtained in Expts 2 and 3 and given in Table 1 are presented both in absolute amounts $(\mathrm{kJ} / \mathrm{d})$ and in terms of the heat produced per unit metabolic size 


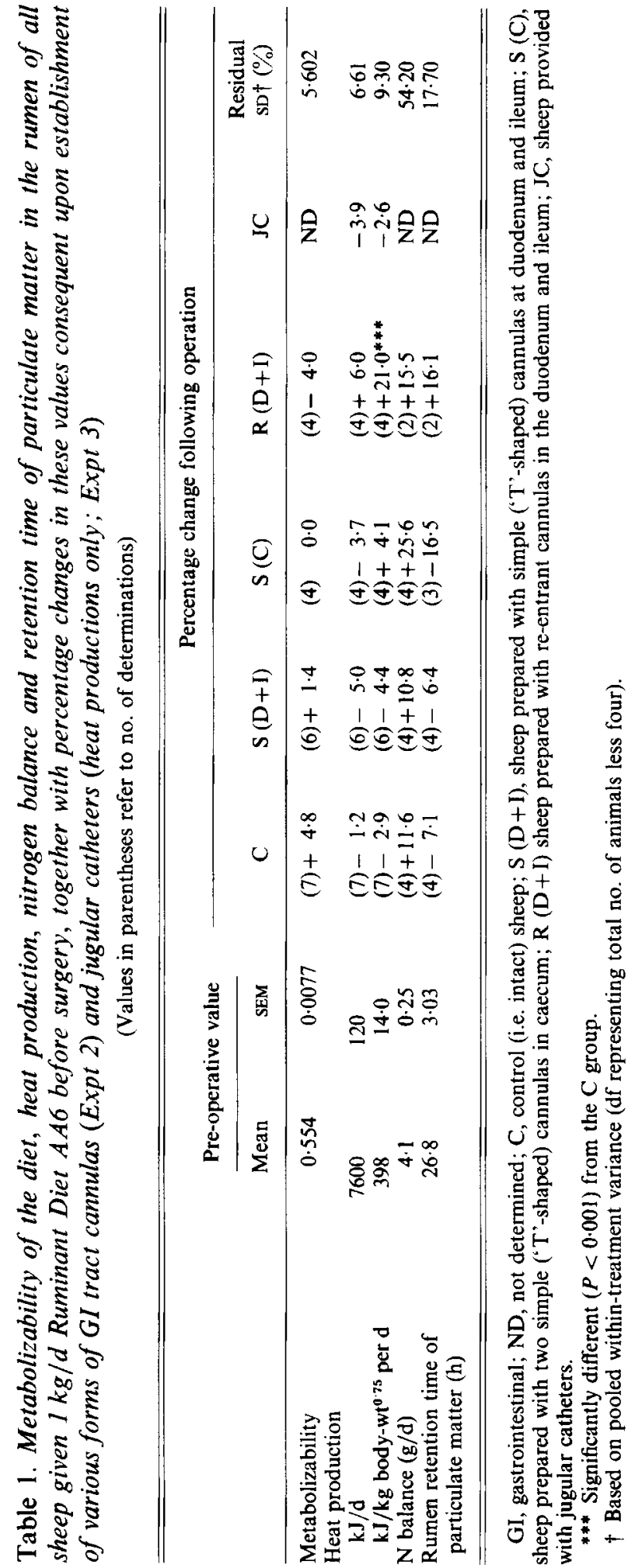


Sheep no. ...

2

3

4
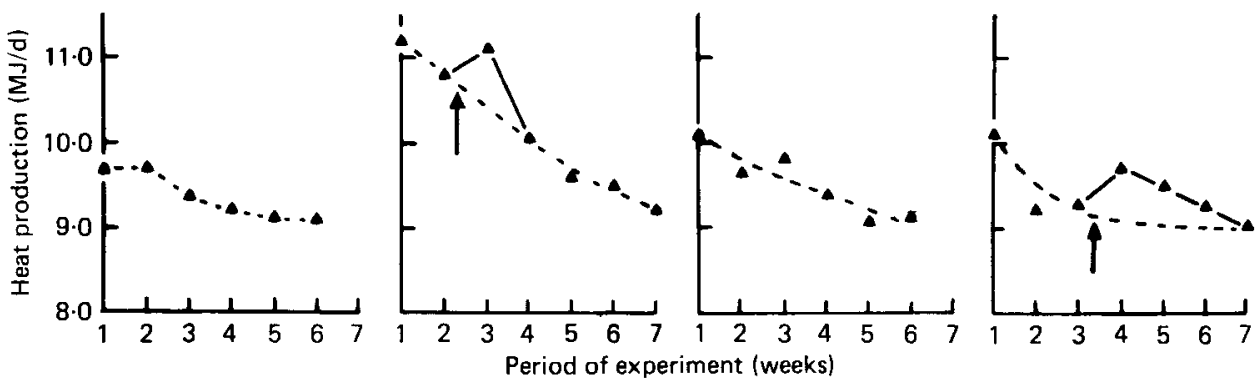

Fig. 1. Changes in heat production $(\mathrm{kJ} / \mathrm{d})$ in four sheep, two of which underwent experimental laparotomy $(\uparrow)$.

$\left(\mathrm{kJ} / \mathrm{kg} \mathrm{W}^{0-75}\right)$. Both sets of values are given because, whilst most animals showed little change in weight from pre- to post-surgery observations (i.e. less than $3 \mathrm{~kg}$ ), all four sheep prepared with re-entrant cannulas were lighter in the post-surgery period $(6-13 \mathrm{~kg})$. All sheep were given the standard daily ration of $1 \mathrm{~kg}$ Ruminant Diet AA6 and so it is arguable as to which basis is the more valid one to use when assessing any changes which occurred as a consequence of surgery.

There were no significant differences between any group means in the pre-surgery phase or between pre- and post-surgery within-animal changes for any treatments in Expt 2 other than the re-entrant cannulations, irrespective of the basis used for the comparison. One of the four sheep prepared with re-entrant cannulas was $13 \mathrm{~kg}$ lighter during its measurement period following surgery and had a heat production which was $130 \mathrm{~kJ}$ less than the pre-surgery measurements, the other three animals which were 6,8 and $11 \mathrm{~kg}$ lighter following surgery had heat productions which were 318,971 and $795 \mathrm{~kJ} / \mathrm{d}$ higher than their pre-surgery values. The mean change in their absolute heat productions following surgery $(487 \pm 249 \mathrm{~kJ} / \mathrm{d})$ was not significantly different $(P<0 \cdot 1)$ from the changes in absolute heat productions observed in the intact animals over the corresponding period $(-119 \pm 177 \mathrm{~kJ} / \mathrm{d})$. However, because of the weight changes which occurred following re-entrant cannulation, when these values are converted to a metabolic body size basis (i.e. the normal way of presenting energy expenditure values) both the changes in absolute heat production $\left(80 \pm 10 \cdot 5 \mathrm{~kJ} / \mathrm{kg} \mathrm{W}^{0 \cdot 75}\right.$ per d) and the percentage changes from pre-surgery values $(+21 \cdot 0 \pm 4 \cdot 6)$ were both highly significantly different $(P<0.01)$ from corresponding values for the control group $\left(-15 \pm 12.8 \mathrm{~kJ} / \mathrm{kg} \mathrm{W}^{0.75}\right.$ per $\mathrm{d} ;-2.9 \pm 3.52$ respectively).

The jugular catheterizations carried out in Expt 3 had no observable effect on the energy expenditure of the four sheep tested.

\section{DISCUSSION}

The intensive study of digestive functions in ruminants was greatly aided by the introduction of surgical techniques which allow collection of GI tract digesta from live animals (for early developments, see Phillipson, 1952; Hogan \& Phillipson, 1960; Harris \& Phillipson, 1962; for reviews of information obtained from such preparations, see Armstrong \& Beever, 1969; Kay, 1969; Phillipson, 1972; MacRae, 1975; Faichney, 1975; Armstrong, 1980).

Re-entrant cannulas were for some years considered the most favourable means of sampling digesta which entered and left the small intestine because they provided a more representative sample than could be obtained from simple (' $T$ '-shaped) cannulas (see MacRae, 1975). However, the introduction of new digesta phase markers such as ${ }^{144} \mathrm{Ce}$ 
(Huston \& Ellis, 1968) and ${ }^{103}$ Ru phenanthroline (Tan et al. 1971) revolutionized the use of simple cannulas by permitting a far more accurate measurement of the flow of digesta than had been possible with previous markers. Nowadays it is accepted that animals prepared with these cannulas and infused with dual-phase markers (MacRae, 1974; Faichney, 1975, 1980) can provide information which is at least the equal of that obtained from re-entrant cannulas (see MacRae \& Ulyatt, 1972). In terms of preparation and maintenance of the different cannulas, the simples are much less work and for this reason they are nowadays the preparation of choice in many laboratories. However, they do generally require the use of fairly sophisticated methods for measurement of $\gamma$-emitting isotopes and so, possibly for this reason, there is still considerable use of re-entrant cannulated animals.

Animals prepared with re-entrant cannulas rarely seem to thrive as well as those with simple (' $T$ '-shaped) cannulas, and indeed radiological studies in which opaque markers have been introduced into the gut proximal to cannulas have suggested that re-entrant cannulations tend to cause serious alteration to gut motility adjacent to the site of cannulation (Wenham, 1979). However on the few occasions when attempts have been made to examine objectively the digestive performance of cannulated and intact animals the results have failed to support any such reservations. Thus the $\mathrm{N}$ metabolism and digesta flow values obtained in the present study are in agreement with previous findings that neither simple (' $T$ '-shaped) cannulas nor re-entrant cannulas appear to alter significantly the digestive performance of sheep (Reid et al. 1961; MacRae, 1967; MacRae et al. 1973; MacRae \& Wilson, 1977) or their over-all $\mathrm{N}$ metabolism as demonstrated in $\mathrm{N}$ balance trials (MacRae \& Wilson, 1977). Equally, Austen et al. (1977) reported that preparation of cannulas in pregnant cows, i.e. six prepared with a rumen plus duodenal and ileal simples and a further four prepared with a rumen plus a duodenal re-entrant, had little effect on subsequent milk yield in early lactation. It might therefore appear that there is little wrong with using either simple or re-entrant preparations for studies of digestion. On the other hand, the study of MacRae \& Wilson (1977) showed that wool growth was much lower in re-entrant cannulated sheep and so an appraisal of energy as well as $\mathrm{N}$ balance in the different preparations seemed a logical prerequisite to the use of any of them in energy expenditure studies.

The short preliminary experiment carried out in this study (Expt 1, see Fig. 1) showed that inhalation anaesthesia plus surgical manipulation per se had no long-term effect on the energy expenditure of the two sheep which underwent these procedures. Of perhaps equal interest in that experiment was the gradual decline in heat production over the 7-week experiment and the fact that although when the experiment started (i.e. 2 weeks after the animals were brought in from pasture) their heat productions on a standard ration showed a range from 9.72 to $11.15 \mathrm{MJ} / \mathrm{d}$ (coefficient of variation $5.58 \%$ ), after 7 weeks of indoor housing in metabolism crates the energy expenditure of all four sheep was very similar $(9 \cdot 233 \pm 0.055 \mathrm{MJ} / \mathrm{d}$, coefficient of variation $1 \cdot 18 \%)$. This mean over-all reduction in energy expenditure observed over the first 2 months of indoor housing $(10.2 \pm 2.63 \%)$ is of the same order as that reported previously (Blaxter, 1974) for untrained sheep, two of which were kept in respiration chambers for $28 \mathrm{~d}$ and a further two kept in metabolism crates for the same period $(7.9 \pm 0.58 \%)$. Needless to say changes in heat production of this magnitude can confound experimental observations unless adequate pretraining of animals is carried out.

From the heat production values obtained in Expts 2 and 3 it would appear that the efficiency of utilization of metabolizable energy was unaltered when sheep were prepared either with a rumen cannula plus simple (' $T$ '-shaped) cannula of the duodenum and ileum, or with a rumen cannula plus two simple cannulas in the caecum or with jugular vein 
catheters. The latter observation is of interest because Wilson et al. (1979) reported that the glucose homoeostasis of animals prepared with jugular catheters is affected over the first $24 \mathrm{~h}$ after catheterization. Analysis of the first and second $24 \mathrm{~h}$ measurements made in all four sheep in Expt 3 showed no significant difference between these two days (heat production in sheep during the first $24 \mathrm{~h}$ was on average $6 \pm 118 \mathrm{~kJ} / \mathrm{d}$ less than on the subsequent $24 \mathrm{~h}$ ).

The values for the re-entrant cannulated animals would appear to substantiate the earlier concern that this form of cannulation does have some effect on the way the animal utilizes its energy-yielding substrates (see the wool growth changes reported by MacRae \& Wilson, 1977). The elevated heat productions were similar to those reported to occur following elective surgery $(10 \%)$ and multiple bone fractures $(15-30 \%)$ in humans. They are not as high as those reported following major sepsis (20-25\%) and full skin thickness burns (up to $125 \%$ ) (see review by Richards et al. 1978).

No attempt was made to determine how the re-entrant cannulation affected the animals but heat production measurements, although quite precise, are not especially sensitive and so changes of this magnitude $(21 \pm 5.65 \%)$ suggest a major shift in some metabolic function(s); Richards et al. (1978) when reviewing the possible mechanisms involved in the elevation of heat production following injury concluded that further experimentation is needed to determine precisely which facets of heat regulation are affected. The conclusion to be drawn from the present study must be that use of animals prepared with re-entrant duodenal and ileal cannulas would not be advised in experiments where values are to be related to other measurements from intact animals. On the other hand, the experiments do appear to validate the post-operative normality of animals prepared with simple cannulas, placed either in the duodenum and ileum or in the caecum, and of animals prepared with jugular catheters. It would therefore appear that this type of cannulation could be used in integrated experiments which involve measurement of digestive criteria using GI cannulations, measurements of metabolite turnover using tracer kinetics and measurement of whole-animal experiments using calorimetry.

The authors would like to thank Messrs. C. Simpson and J. F. Ingram for helping with surgical anaesthesia and Messrs P. J. S. Dewey, J. F. Ingram, A. Walker and other members of the Energy Metabolism Department for helping with animal handling and analyses. They are also indebted to Dr J. G. Gordon for measuring the heat losses in Expt 1.

\section{REFERENCES}

Armstrong, D. G. (1980). 2nd Tom Miller Memorial Lecture, School of Agriculture, Aberdeen.

Armstrong, D. G. \& Beever, D. E. (1969). Proc. Nutr. Soc. 28, 121.

Austen, P., Buttle, H. L., Corse, D. A., Cowie, A. T., Johnson, V. W., Oldham, J. D., Sutton, J. D. \& Watson,

S. C. (1977). Z. Tierphysiol., Tierernahrg. u. Futtermittelkde 39, 192.

Blaxter, K. L. (1974). Pubs Eur. Ass. Anim. Prod. no. 14, p. 115.

Brown, G. F., Armstrong, D. G. \& MacRae, J. C. (1968). Br. vet. J. 124, 78.

Davidson, J., Matheson, J. \& Boyne, A. W. (1970). Analyst, Lond. 95, 181.

Drori, D. \& Loosli, J. K. (1959). J. Anim. Sci. 18, 206.

Faichney, G. J. (1975). In Digestion and Metabolism in the Ruminant, p. 277 [I. W. McDonald and A. C. I. Warner, editors]. Armidale, Australia: University of New England Publishing Unit.

Faichney, G. J. (1980). J. agric. Sci., Camb. 94, 313.

Grovum, W. L. \& Williams, V. J. (1973). Br. J. Nutr. 30, 313.

Harris, L. E. \& Phillipson, A. T. (1962). Anim. Prod. 4, 97.

Hayes, B. W., Little, C. O. \& Mitchell, G. E. J. (1964). J. Anim. Sci. 23, 764.

Hecker, J. F. (1974). In Experimental Surgery on Small Ruminants, p. 126. London: Butterworths.

Hogan, J. P. \& Phillipson, A. T. (1960). Br. J. Nutr. 14, 147.

Huston, J. E. \& Ellis, W. G. (1968). J. agric. Fd Chem. 16, 225.

Kay, R. N. B. (1969). Proc. Nutr. Soc. 28, 140.

Kay, R. N. B. \& McKenzie, J. D. (1968). J. Sci. Technol. 14, 15. 
McDonald, J. D., MacRae, J. C. \& McKenzie, J. D. (1979). Lab. Pract. 28, 1317.

MacRae, J. C. (1967). Carbohydrate digestion in the intestinal tract of the mature sheep. PhD Thesis, University of Newcastle-upon-Tyne.

MacRae, J. C. (1974). Proc. Nutr. Soc. 33, 147.

MacRae, J. C. (1975). In Digestion and Metabolism in the Ruminant, p. 261 [I. W. McDonald and A. C. I. Warner, editors]. Armidale, Australia: University of New England Publishing Unit.

MacRae, J. C., Reid, C. S. W., Dellow, D. W. \& Wyburn, R. S. (1973). Res. vet Sci. 14, 78.

MacRae, J. C. \& Ulyatt, M. J. (1972). N. Z. Jl Agric. Res. 15, 98.

MacRae, J. C. \& Wilson, S. (1977). Br. J. Nutr. 38, 65.

Phillipson, A. T. (1952). J. Physiol., Lond. 116, 84.

Phillipson, A. T. (1972). Proc. Nutr. Soc. 31, 159.

Pullar, J. D. (1969). In Nutrition of Animals of Agricultural Importance, part 1, p. 471 [D. Cuthbertson, editor]. Oxford: Pergamon Press.

Putman, P. A. \& Davis, R. E. (1965). J. Anim. Sci. 24, 826.

Reid, R. L., Shelton, D. C. \& Welch, J. A. (1961). In Reactions in the Rumen p. 37 [A. J. G. Barnett \& R. L. Reid, editors]. London: Edward Arnold.

Richards, J. R., Drury, J. K., Goll, C., Bessent, R. G. \& Al-Shamma, G. A. A. (1978). Proc. Nutr. Soc. $37,29$.

Tan, T. N., Weston, R. H. \& Hogan, J. P. (1971). Int. J. appl. Radiat. Isotopes 22, 301.

Wainman, F. W. \& Blaxter, K. L. (1969). In Energy Metabolism of Farm Animals, p. 429 [Blaxter, K. L., Kielanowski, J. \& Thorbek, G., editors]. Newcastle upon Tyne: Oriel Press.

Wenham, G. (1979). Ann. Rech. Vet. 10, 157.

Wilson, S., MacRae, J. C. \& Buttery, P. J. (1979). Res. vet. Sci. 26, 256. 